\title{
Changes of academic performance by integration between basic and clinical medicine in pre-clerkship medical education
}

\author{
So Jung Yune ${ }^{1}$ and Jin Sup Jung ${ }^{2}$ \\ Departments of ${ }^{1}$ Medical Education and ${ }^{2}$ Physiology, Pusan National University School of Medicine, Yangsan, Korea
}

Purpose: The purpose of this study was to investigate the effect of curriculum revision on student performance in tests of the medical knowledge of students at Pusan National University.

Methods: Test scores of the Basic Medicine Comprehensive Examination (BMCE), conducted by the Medical Education Assessment Corporation, and internal clinical knowledge tests of the three integrated courses of the Pusan National University School of Medicine, during the last 3 years (2015-2017) were compared with an unpaired Student t-test and the results were considered to be significant at $p<0.05$.

Results: Curriculum revision in 2017 introduced the integration of basic and clinical courses at the organ level of medical education. Scores of BMCE and internal clinical knowledge tests in three integrated courses after curriculum revision showed a statistically significant increase after curriculum revision.

Conclusion: Curriculum revisions that integrated the basic and clinical courses in organ-level education improved student's academic performance significantly.

Key Words: Curriculum, Undergraduate medical education, Academic achievement

\section{Introduction}

Flexner [1] in 1910 proposed a binary structure for the medical education curriculum in which students develop the scientific foundation of medicine during the first 2 years of medical school, followed by a clinical clerkship for the remaining 2 years to accumulate actual patient experience. This has become a major paradigm of the medical school curriculum and is now used worldwide [2]. However, it has been pointed out that this education system is inadequate for the training of physicians who must keep pace with such changes in medical environments in the 21st century as the importance of cooperative medical care, changes in health care policy, medical delivery systems, and the Fourth Industrial Revolution [3-5].

Adult learning theories indicates that adults are most interested in learning of practical subjects that have immediate relevance and impact to their professional or personal needs [6-8]. In fact, it has been shown that the probability of knowledge transfer increased when basic
Received: April 6, 2018 • Revised: June 12, 2018 • Accepted: July 3, 2018

Corresponding Author: Jin Sup Jung (https://orcid.org/0000-0002-7643-0918)

Department of Physiology, Pusan National University School of Medicine, 49 Busandaehak-ro, Mulgeum-eup, Yangsan 50612, Korea

Tel: +82.51.510.8071 Fax: +82.51.510.8076 email: jsjung@pusan.ac.kr
Korean J Med Educ 2018 Sep; 30(3): 209-218.

https://doi.org/10.3946/kjme.2018.95

eISSN: 2005-7288

(C) The Korean Society of Medical Education. All rights reserved. This is an open-access article distributed under the terms of the Creative Commons Attribution Non-Commercial License (http:// creativecommons.org/licenses/by-nc/3.0/), which permits unrestricted non-commercial use, distribution, and reproduction in any medium, provided the original work is properly cited. 
medical knowledge was taught based on the clinical context compared with cases where the principles and concepts of basic medicine were not linked with clinical situations [9,10]. Knowledge and understanding in medical education is more readily developed when explained within the relevant clinical context [11]. Furthermore, teaching approaches that is linked with clinical contexts facilitates students to develop a deeper understanding of medical knowledge that may be more readily retrieved and transferred to various situations [11]. Therefore, it is recommended that integrated education linked to its clinical context be implemented to effectively learn rapidly expanding medical knowledge, and the Global Alliance for Medical Education has encouraged the development of a curriculum that integrates basic and clinical medicine centered on core knowledge [12]. In line with a tendency to integrate basic and clinical medical subjects around the world [3], the number of medical schools that have introduced an integrated curriculum system has also been increasing in Korea [13].

One method of teaching medical knowledge is to separate integrated courses of basic medical subjects such as anatomy, pathology, and pharmacology in the first year from those of clinical subjects in the second year. Another way is to provide an integrated education in basic and clinical medical subjects according to organ systems. However, if the contents of basic and clinical medicine within an integrated course are not organized effectively, it is difficult to accomplish improvement of students' academic performance which is one of important purposes of integration. In this case, students and professors still feel that basic and clinical education within a course are separated, not integrated [14]. Many professors teaching basic medicine tend to think that basic medical education is weakened in the vertical integration model. As a result, the majority of domestic medical schools have retained the former curriculum, and only a few universities use the latter.

Pusan Medical University revised its pre-clerkship medical curriculum in 2006, which was organized so as to have integration courses for basic medicine subjects in the first year and clinical medicine subjects in the second year, and operated this system until 2016. During the operation of the existing curriculum, the problems were found that the connections between basic medical knowledge and clinical knowledge had been getting weaker and related subjects were scattered throughout various courses in the education schedule. Therefore, Pusan National University began to reform its medical school curriculum in 2015 and implemented a new curriculum in 2017. The major change in the new curriculum is to place the foundation of medicine in the first semester of the first year and offer organ-systembased integrated courses uniting basic and clinical medicine from the second semester of the first year to the second semester of the second year.

In this study, we evaluated the changes in student performance on tests of medical knowledge due to the integration of preclinical and clinical subjects for the pre-clerkship medical education at Pusan National University. The changes in performance in basic medical knowledge were determined by an analysis of scores on the Basic Medicine Comprehensive Examination (BMCE), conducted by Medical Education Assessment Corporation, while the changes in performance in clinical medical knowledge were analyzed by comparing the gastroenterology, cardiovascular medicine, and respiratory medicine scores for students entering in 2015, 2016, and 2017.

The two overarching research questions guiding the study were as follows. (1) What are the changes of basic medicine academic performance by curriculum revision? (2) What are the changes of clinical medicine academic performance by curriculum revision? 


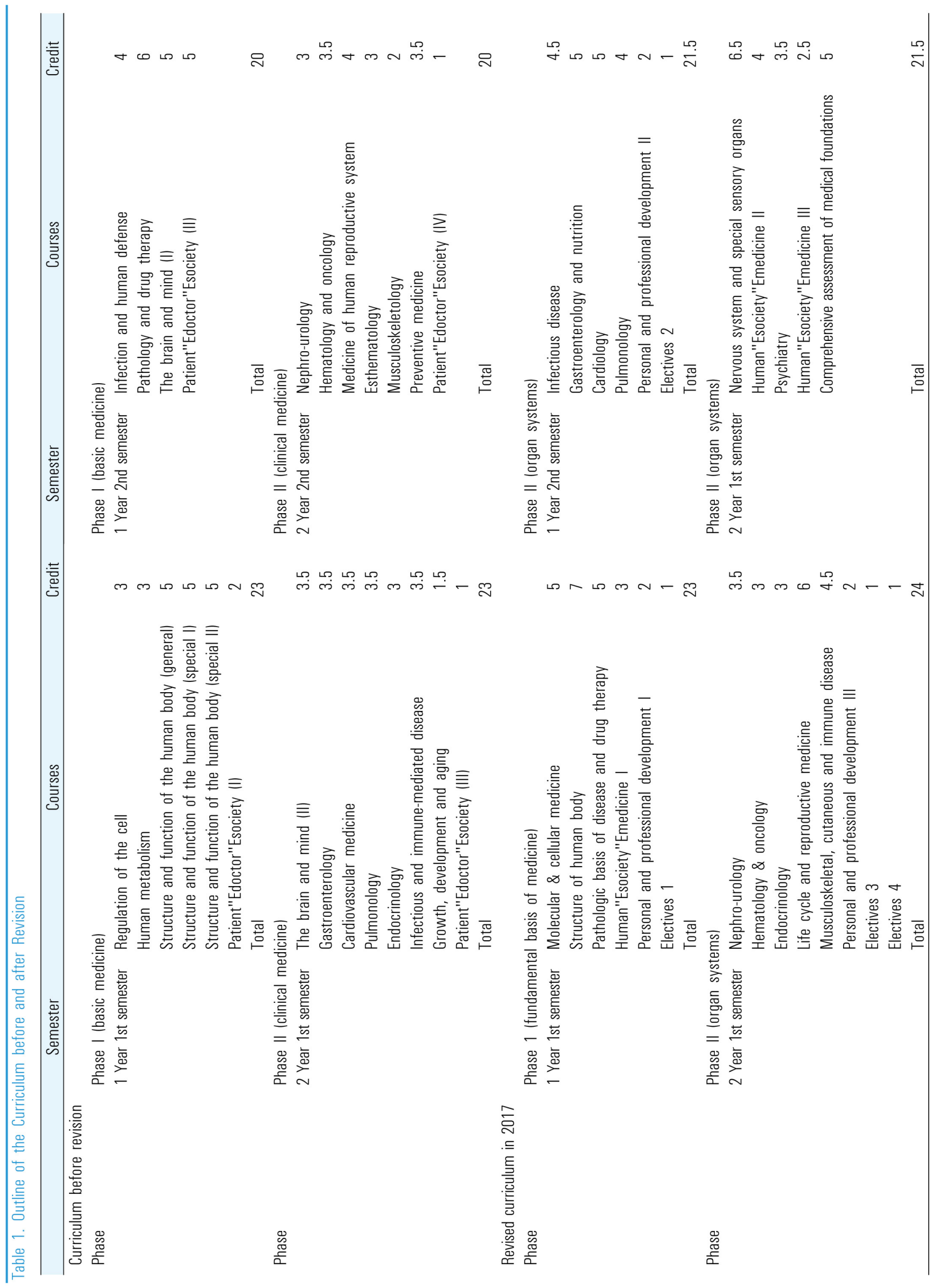




\section{Methods}

\section{Participant and data}

The subjects of this study were students of the medical college and medical school at Pusan National University. This study was reviewed and given exempt status by the Institutional Review Board of Pusan National University (PNU IRB/2018_33_HR). Students were excluded from the study if they had missed any examinations or failed courses during the study period. To minimize the variation in the comparison of scores by year, we also excluded return students who took the same courses twice. The number of subjects was as follows: 110 students entering in 2017, 118 students entering in 2016, and 112 students entering in 2015. All students in 2015 and 2016 transferred in after graduating from a 4-year college. In 2017, there were 75 students transferred in from a pre-med course, and 35 students transferred in after graduating from a 4-year college.

\section{Materials}

The research tools used in this study were the internal evaluation scores and the BMCE scores of medical students who entered Pusan National University from 2015 to 2017. And the clinical course scores of the gastroenterology, cardiovascular, and respiratory courses were compared before and after curriculum revision. Table 1 summarizes the curriculum before revision. The pre-revision curriculum consisted of the integration of basic medical disciplines in the first year and the integration of clinical disciplines in the second year. Neuropsychology in the second semester of the first year was an integrated course bridging related subjects in basic medicine, including neuroanatomy and neurophysiology, and related clinical subjects, including clinical neurology and psychiatry. Table 1 shows the curriculum that was revised in 2017. The first semester of the first year is the foundation of medicine, which includes anatomy, biochemistry, genetics, molecular and cell biology, including membrane transport and electrical phenomena in cell membranes, immunology, introduction to embryology, histology, pathology, and pharmacology, and the introduction to epidemiology and preventive medicine. From the second semester of the first year to the second semester of the second year, the curriculum consisted of integrated courses including embryology, histology, physiology, pathology, microbiology, parasitology, and clinical subjects for each organ system.

As the curriculum timetable shows (Table 1), clinical education in the corresponding courses was carried out in the first semester of the second year before the curriculum revision, but in the second semester of the first year after the curriculum revision. Therefore, the above three subjects were judged to be suitable for comparing the academic performance before and after the curriculum revision. After the curriculum revision, each course contained basic medical education content, scores on which were reflected in the course scores. Thus, in order to compare the results with those of the first semester of the second year, only the scores on questions from the clinical professors in the second semester of the first year were compared. Because subjective questions were difficult to standardize, only the results of the multiple choice questions were selected for comparative analysis. In order to analyze the factors that may affect test scores, we compared the total clinical lecture hours, the number of clinical lecturers, the number of objective questions, the similarity with previous questions between 2016 and 2017 students, item discrimination, and item difficulty in the above three subjects (Table 2). The amount of clinical lecture time 
decreased by 2 to 8 hours after the curriculum revision, and the number of lectures and objective questions and the proportion of similar questions with the previous examinations were similar between 2016 and 2017 students. And also there was no difference in item discrimination and difficulty between 2016 and 2017 (Table 2). Among the students who participated in the BMCE in 2015 and 2016, the students who failed subjects in the first year or were absent from some subjects during the second year were excluded from the analysis of clinical scores. Therefore, the number of students who were included in the clinical score evaluation among students entering in 2015 and 2016 decreased to 115 and 107 , respectively, from those who participated in the BMCE.

For the internal evaluation tools, the results of the clinical multiple choice tests of the gastroenterology, respiratory, and cardiovascular courses were analyzed by comparison before and after curriculum revision in the department of medicine. In order to ensure the validity of the evaluation tools, medical education center analyze the item similarity with the previous test questions before the test, and analyze the degree of difficulty and discrimination after the test. Students' individual test scores on the BMCE, which was taken at the end of the first year, were also taken for analysis. In order to evaluate the similarity of the test items to the previous test questions, the test questions for 3 to 4 years prior to the last semester were analyzed using the Turnitin program (Turnitin LLC., Oakland, USA), then the items that were marked as similar in an analysis file were directly checked so that a final judgment could be made as to whether they were similar to the previous test questions.

\section{Analysis of the results}

In order to analyze academic performance according to 
the revised curriculum, we analyzed the differences in the test scores between the 2 years before and 1 year after curriculum revision. Data represent mean \pm standard deviation. Data analysis in this study was performed with Student t-testing using Graphad QuickCalcs (Graphpad software Inc., La Jolla, USA). The statistical significance of the analysis results was defined as a significance level of less than $5 \%$.

\section{Results}

\section{Basic Medicine Comprehensive Exami- nation score analysis}

Taking into account the integration of the basic medical subjects into the organ system courses and the educational period, they were classified into three groups as anatomy and biochemistry, which were taught separately from clinical subjects in the first semester of the first year; physiology, pathology, and pharmacology, which were partly taught with the related clinical subjects; and microbiology, which was taught with the related clinical subjects. Parasitology scores were included in pathology scores due to being taken during the same examination hour. The anatomy and biochemistry scores were the lowest in 2016, but there was no statistically significant difference by year. In contrast, scores for physiology, pathology, and pharmacology, which were taught integrated with clinical subjects, were significantly higher in 2017 than in either 2015 or 2016, and microbiology in 2017 showed similar results (Table 3). The difference between the average scores and the national average scores was significantly higher in 2017 than in 2016, and there was no significant difference compared to 2015 (Table 3).

In the case of BMCE, the percentage of the contents that were not educated in physiology, pathology, or pharmacology, such as the blood, kidney, endocrine, reproductive, and musculoskeletal systems, was about $30 \%$. In the case of physiology, the uncovered questions that had not been learned (12 out of 35 items) made up $34.2 \%$ of the total questions, and the corrected difficulty of uncovered items was significantly lower than that of the learned questions on the subjects (0.20 versus 0.52$)$.

\section{Clinical test results analysis}

In order to evaluate academic performance in some of the clinical courses, the clinical course scores of the gastroenterology, cardiovascular, and respiratory courses were compared before and after curriculum revision.

For the total average scores of gastroenterology, respiratory, and cardiovascular courses, the scores of the students entering the school in 2017 after curriculum revision were significantly higher than those in 2015 and 2016. There were no significant differences between the

\begin{tabular}{lccccc}
\hline \multicolumn{2}{l}{ Table 3. Analysis of the Basic Medicine Comprehensive Examination } & according to Subjects & & \\
\hline \multicolumn{1}{c}{ Year } & No. of students & $\begin{array}{c}\text { Anatomy/ } \\
\text { biochemistry }\end{array}$ & $\begin{array}{c}\text { Physiology/pathology/ } \\
\text { pharmacology }\end{array}$ & Microbiology & Total average \\
\hline 2017 & 109 & $2.92 \pm 10.54$ & $5.32 \pm 9.14$ & $0.09 \pm 11.33$ & $2.75 \pm 9.01$ \\
p-value vs. 2016 & & 0.0829 & $<0.0001$ & $<0.0001$ & $<0.0001$ \\
p-value vs. 2015 & & 0.3898 & $<0.0001$ & 0.0119 & 0.1235 \\
2016 & 118 & $0.84 \pm 7.26$ & $-4.63 \pm 8.02$ & $-7.76 \pm 9.21$ & $-2.41 \pm 6.63$ \\
p-value vs. 2015 & & 0.0018 & $<0.0001$ & $<0.0001$ & $<0.0001$ \\
2015 & 112 & $4.00 \pm 7.90$ & $0.23 \pm 7.07$ & $-3.29 \pm 8.23$ & $1.14 \pm 6.26$ \\
\hline
\end{tabular}

Data are presented as number or mean \pm standard deviation. 
students entering school in 2015 and 2016 except for the scores in the cardiovascular courses. The results of the analysis of the correlation between the average scores on the clinical test and the average scores on the BMCE showed a significant correlation during the period analyzed in this study. Although the differences among the correlation coefficients of each course were not statistically significant, the Pearson correlation coefficient in 2017 was the highest (Table 4).

In order to ascertain whether the increase in scores of the first-year BMCE and the clinical test results in 2017 was due to the change of student composition, that is, the presence of students who entered from the pre-med course, the scores of the students who entered from the pre-med course and the transfer students who had graduated from a university were compared. In the case of the BMCE, the transfer students' scores were statistically significantly higher than those of the students from the pre-med course. Although there was no statistical significance, the average scores for the clinical tests for the cardiovascular, respiratory, and gastroenterology courses were higher than those of the students from the pre-med course (Table 5).

\section{Discussion}

The purpose of this study was to analyze the effects of curriculum revision on student academic performance in a medical school in Pusan and to draw implications for future curriculum revision. To this end, we compared student scores on internal and external evaluations before and after the revision of the curriculum.

The results were as follows. First, the scores on the BMCE improved after the curriculum revision. BMCE scores were not reflected in student's grade before curriculum revision, and passing the BMCE was one of graduation requirements. The BMCE scores at the end of

Table 4. Analysis of Clinical Course Scores by Courses

\begin{tabular}{lcccccc}
\hline \multicolumn{1}{c}{ Year } & No. of students & Cardiovascular & Respiratory & Gastroenterology & $\begin{array}{c}\text { Average of three } \\
\text { subjects }\end{array}$ & $\begin{array}{c}\text { Correlation } \\
\text { coefficient between } \\
\text { average and BMCE }\end{array}$ \\
\hline 2017 & 110 & $74.48 \pm 7.26$ & $85.44 \pm 6.20$ & $80.30 \pm 5.88$ & $80.07 \pm 5.84$ & 0.665 \\
p-value vs. 2016 & & 0.0889 & $<0.0001$ & 0.0003 & 0.006 & $<0.00001$ \\
p-value vs. 2015 & 115 & $76.13 \pm 7.19$ & $80.08 \pm 7.54$ & $76.99 \pm 7.57$ & $77.73 \pm 6.76$ & 0.539 \\
2016 & & 0.0004 & 0.1882 & 0.2666 & 0.2094 & $<0.00001$ \\
p-value vs. 2015 & 107 & $72.63 \pm 7.29$ & $81.35 \pm 6.35$ & $75.86 \pm 7.48$ & $76.61 \pm 6.48$ & 0.525 \\
2015 & & & & & $<0.0001$ & $<0.0001$ \\
p-value & & & & & $<0001$ \\
\hline
\end{tabular}

Data are presented as number or mean \pm standard deviation. 2017 vs. 2016: correlation coefficient $z=1.47$, one-tailed =0.0708, two-tailed =0.1429; 2017 vs. 2015: correlation coefficient $z=1.58$, one-tailed $=0.0571$, two-tailed $=0.1134$.

BMCE: Basic Medicine Comprehensive Examination.

Table 5. Scores of Pre-Med Students and Transfer Students

\begin{tabular}{lcccccc}
\hline \multicolumn{1}{c}{2017} & No. of students & BCME & Cardiovascular & Respiratory & Gastroenterology & $\begin{array}{c}\text { Average of three } \\
\text { subjects }\end{array}$ \\
\hline Pre-med students & 75 & $1.21 \pm 9.09$ & $74.27 \pm 7.47$ & $84.40 \pm 6.51$ & $80.06 \pm 6.21$ & $79.58 \pm 6.11$ \\
Transfer students & 35 & $6.00 \pm 8.03$ & $74.93 \pm 6.85$ & $87.66 \pm 4.83$ & $80.80 \pm 5.13$ & $81.13 \pm 5.14$ \\
p-value & & 0.0089 & 0.6608 & 0.0094 & 0.5399 & 0.1949 \\
\hline
\end{tabular}

Data are presented as number or mean \pm standard deviation.

BMCE: Basic Medicine Comprehensive Examination. 
1st grade are taken into account as $20 \%$ of comprehensive assessment of medical foundation (5 credits) in the revised curriculum. Therefore, the change in the way that BCME scores are reflected by curriculum revision may partly contribute to improvement of BMCE scores. However, the scores in physiology, pathology, pharmacology, and microbiology, which were integrated with the clinical subjects, were improved significantly compared to those of the subjects before the curriculum revision. Among these, physiology, pathology, and pharmacology showed particularly notable score increase even though about $30 \%$ of the questions had not been covered due to the curriculum arrangement. The improvement on the BMCE scores may mainly have resulted from the integrated education of basic and clinical context under the revised curriculum, because most questions on the BMCE were linked to clinical contexts.

Second, the evaluation after the curriculum revision showed that the average scores of cardiovascular medicine, respiratory medicine, and gastroenterology were significantly higher than before curriculum revision, although there were no significant differences in the average scores of these subjects of the 2015 and 2016 students. The grades might change due to the difficulty of the items and changes of the professors setting the questions depending on the year of study. However, the lecture hours, the number of lecturer, the similarity of questions with the previous examination, item discrimination and item difficulty after curriculum revision were similar with those before the curriculum revision, and there was no significant difference between the clinical scores in the 2015 and 2016 students. Therefore, the increase in the clinical scores after curriculum revision may be related to the curriculum revision. Among 2017 students, about 70\% entered from the pre-med department and about 30\% transferred after university graduation, while all students in 2015 and 2016 consisted of university graduates. However, the data in this study show that the scores on the clinical subjects of the transfer students were similar to those of pre-med students and their BCME scores were even higher than the BCME scores of pre-med students. Therefore, the results cannot be interpreted as due to a change in the composition of students due to changes in the entrance system.

The vertical integration curriculum has the advantage of motivating students to study in depth. This is the same in both basic medicine and clinical medicine. In the vertical integration curriculum, students try to better understand biological principles and mechanisms [15]. Through the links between basic and clinical medicine, students increase their intellectual curiosity and retention of knowledge [16]. In some studies, students' satisfaction with vertical integration curriculum was high. The students felt that they learned more deeply through clinical cases, and they were motivated to go back and read basic medicine to solve problems [15-17]. In this respect, the results of this study can be easily understood.

It takes a lot of time and effort to plan, organize and operate the curriculum vertically. If the integrated education is limited to the simple rearrangement of the contents of related subjects, the effect of integration does not appear [18]. There was a real concern that if the basic and clinical classes are integrated, basic medicine, which had a relatively short teaching time, might be neglected by students. In spite of these concerns, the integrated education of preclinical and clinical subjects at Pusan National University did not weaken the students' performance on basic medical education, but rather had a positive effect on the BCME scores and clinical medical scores even though it was a short-term analysis of their performance. 
This study had the following limitations. First, we only analyzed the scores for 1 year after the curriculum revision. Therefore, it may be difficult to conclude that the increase in test scores was due to the curriculum revision. Even within these limitations, however, this study suggests that integration of related basic and clinical medicine subjects in the curriculum revision did not lead to a deterioration in the performance in basic medical knowledge, but may help it. Second, in the case of the clinical test scores it was difficult to completely standardize the difficulty level of the test items through quantitative analysis. Therefore, it is difficult to completely rule out the possibility of score differences due to differences in the level of difficulty of the set of items for each subject. The results of this study suggest that the curriculum and its operation should continue to be improved through continuous monitoring of students' academic performance and quality control of the evaluation process.

\section{ORCID:}

So Jung Yune: https://orcid.org/0000-0002-2567-0444;

Jin Sup Jung: https://orcid.org/0000-0002-7643-0918

Acknowledgements: None

Funding: This work was supported by a 2-year research grant of Pusan National University.

Conflicts of interest: No potential conflict of interest relevant to this article was reported.

Author contributions: Design and implementation of the work: JSJ; data collection: SJY; drafting the article: SJY, JSJ; reviewing the final version before submission; JSJ; and final approval of the version to be published: SJY, JSJ.

\section{References}

1. Flexner A. Medical education in the United States and Canada: a report to the Carnegie Foundation for the Advancement of Teaching. Boston, USA: Updike; 1910.

2. Boudreau JD, Cassell EJ. Abraham Flexner's “mooted question" and the story of integration. Acad Med. 2010;85(2):378-383.

3. Cooke M, Irby DM, Sullivan W, Ludmerer KM. American medical education 100 years after the Flexner report. N Engl J Med. 2006;355(13):1339-1344.

4. Irby DM, Cooke M, O'Brien BC. Calls for reform of medical education by the Carnegie Foundation for the Advancement of Teaching: 1910 and 2010. Acad Med. 2010;85(2):220-227.

5. Maeshiro R, Johnson I, Koo D, et al. Medical education for a healthier population: reflections on the Flexner Report from a public health perspective. Acad Med. 2010;85(2):211-219.

6. Knowles MS. Andragogy in action: applying modern principles of adult learning. San Francisco, USA: Jossey-Bass; 1984.

7. Mezirow J. Learning to think like an adult: core concepts of transformation theory. In: Taylor EW, Cranton P, eds. The Handbook of Transformative Learning: Theory, Research and Practice. San Francisco, USA: Jossey-Bass; 2000:35-70.

8. Taylor DC, Hamdy H. Adult learning theories: implications for learning and teaching in medical education: AMEE guide no. 83. Med Teach. 2013;35(11): e1561-e1572.

9. Catrambone R, Holyoak KJ. Overcoming contextual limitations on problem-solving transfer. J Exp Psychol Learn Mem Cogn. 1989;15(6):1147-1156.

10. Quilici JL, Mayer RE. Role of examples in how students learn to categorize statistics word problems. J Educ 
Psychol. 1996;88(1):144-161.

11. Bransford JD, Brown AL, Cocking RR. How people learn: brain, mind, experience, and school: expanded edition. Washington, USA: National Academy Press; 2000.

12. The Executive Council, The World Federation for Medical Education. International standards in medical education: assessment and accreditation of medical schools': educational programmes: a WFME position paper. Med Educ. 1998;32(5):549-558.

13. Dahle LO, Brynhildsen J, Behrbohm Fallsberg M, Rundquist I, Hammar M. Pros and cons of vertical integration between clinical medicine and basic science within a problem-based undergraduate medical curriculum: examples and experiences from Linköping, Sweden. Med Teach. 2002;24(3):280-285.

14. Rajan SJ, Jacob TM, Sathyendra S. Vertical integration of basic science in final year of medical education. Int J Appl Basic Med Res. 2016;6(3):182-185.
15. Ahn DS. The past, present, and future of basic medical education. Paper presented at: 19th Federation Meeting of Korean Basic Medical Scientists; May 13-14, 2011; Seoul, Korea.

16. Yang E, Ahn D. A strategy to activate the basic science education in medical school. Hanyang Med Rev. 2012;32(1):25-29.

17. Kulasegaram KM, Martimianakis MA, Mylopoulos M, Whitehead CR, Woods NN. Cognition before curriculum: rethinking the integration of basic science and clinical learning. Acad Med. 2013;88(10):15781585.

18. Brynhildsen J, Dahle LO, Behrbohm Fallsberg M, Rundquist I, Hammar M. Attitudes among students and teachers on vertical integration between clinical medicine and basic science within a problem-based undergraduate medical curriculum. Med Teach. 2002;24(3):286-288. 